\title{
Bacitracin Action on Membranes of Mycobacteria
}

\author{
By M. RIEBER, T. IMAEDA AND I. M. CESARI \\ Department of Microbiology, Instituto Venezolano de Investigaciones Cientificas, \\ Apartado 1827, Caracas, Venezuela
}

(Accepted for publication 9 September 1968)

SUMMARY

Bacitracin at concentrations of 6.5-13.0 $\mu \mathrm{g}$. $/ \mathrm{ml}$. inhibited the growth of Mycobacterium smegmatis ATCC 607. Concentrations Io times higher were required to produce a similar effect on $M$. tuberculosis BCG. Assays of the bacitracin effect in Sauton medium showed no significant drug inhibition due to the cancelling effect of citrate ions present in this medium. Low concentrations of bacitracin produced smooth-surface colonies consisting of bacteria which showed a modified cell-wall appearance, in contrast to the rough colonies formed by control bacteria. Ultrastructure studies indicated that the main target of bacitracin action on mycobacteria may be a direct effect on the membrane system.

\section{INTRODUCTION}

Studies on the action of bacitracin on Gram-positive bacteria have shown the antibiotic to possess a variety of biological activities, such as induction of cell lysis (Smith \& Weinberg, 1962), accumulation of cell-wall intermediates (Abraham \& Newton, 1958), and inhibition of the incorporation of labelled amino acids into cell-wall mucopeptides (Hancock \& Fitz-James, 1964). All these findings suggest that bacitracin acts by interfering with the synthesis of the cell walls of susceptible organisms. Although Sutter \& Vaughan (1955) reported that bacitracin is an effective inhibitor of the growth of Streptomyces bovis, which is taxonomically related to the genus Mycobacterium, no report is available about the action of bacitracin on mycobacteria. It has now been found that when added during the early stages of growth, bacitracin is bactericidal to mycobacteria in vitro. In agreement with its postulated role as a cell-wall antibiotic, the present work shows that bacitracin seems to affect synthesis of the mycobacterial cell wall. The present report also shows that bacitracin acts on mycobacteria by causing marked alterations in their membranous structures.

\section{METHODS}

Stock cultures and organisms. The cultures used in the present experiments were maintained by adding $\mathrm{I} \mathrm{ml}$. of a 4-day stock culture of Mycobacterium smegmatis ATCC 607 to $150 \mathrm{ml}$. of liquid medium. Similar procedures were followed for $M$. tuberculosis BCG which was subcultured by adding inocula from Io-day stock cultures into the corresponding media.

Conditions for growth. The cultures were incubated at $37^{\circ}$ on a reciprocal shaker and growth was followed in triplicate by measuring extinction at $450 \mathrm{~m} \mu(E 450)$ in colorimetric tubes $(2.54 \mathrm{~cm}$.) with a Bausch \& Lomb Spectronic-20 Colorimeter. 
Mycobacterium smegmatis ATCC 607 was studied in (a) Sauton medium containing $2 \%$ glucose instead of glycerol; (b) Penassay medium (Difco Lab., Detroit, Mich.); (c) Middlebrook $7 \mathrm{H}_{9}$ medium (Difco). M. tuberculosis BCG was studied only in Sauton and Penassay media. Tween 80 (polyoxyethylene sorbitan monooleate, Sigma Chemical Co., St Louis, Mo., U.S.A.) was added to all media to a final concentration of $0.05 \%(v / v)$.

The viability of organisms was estimated by plating samples of experimental cultures on brain heart infusion agar (Difco) and incubating at $37^{\circ}$ for 4 to 5 days to allow for the slower growth of bacitracin-treated cultures.

Bacitracin (Sigma) 73.9 units/mg. previously sterilized by filtration was added to the cultures.

Electron microscopy. Bacitracin-treated and control organisms were fixed by a slight modification of the Stoeckenius \& Rowen's method (1967). The salt solution consisted of $5 \%(w / v) ~ N a C l$ plus I $\%(w / v) \mathrm{CaCl}_{2} ; \mathrm{I} \%(\mathrm{w} / \mathrm{v})$ osmium tetroxide was used for post-fixation instead of potassium permanganate. After fixation followed by uranyl nitrate treatment, organisms were dehydrated in graded acetone plus water mixtures and embedded in Araldite. Ultrathin sections were doubly stained with uranyl acetate and lead citrate. An aqueous solution of sodium silicotungstate ( $2 \%$, $\mathrm{w} / \mathrm{v}$ ), at $\mathrm{pH} 7 \cdot 6$, was used for negative staining of unfixed organisms. The material was examined with Hitachi HU-I IB and Jeol JEM-7A electron microscopes.

\section{RESULTS}

\section{Effect of bacitracin on the growth of mycobacteria}

The inhibition caused by bacitracin on the growth of Mycobacterium smegmatis ATCC 607 is shown in Fig. I. When bacitracin was added during the early stages of growth, there was a complete inhibition, at concentrations of $13.0 \mu \mathrm{g}_{\circ} / \mathrm{ml}$. Examination of the viability of the bacteria by plating out concentrated samples showed that bacitracin was highly bactericidal even at $6.5 \mu \mathrm{g}$. $/ \mathrm{ml}$. Addition of bacitracin after the bacteria had reached their exponential stage of growth, did produce some inhibition although not as marked as previously quoted (Fig. I). Bacteria which survived after bacitracin treatment, formed on agar media smooth surface colonies differing from the rough appearance of the control colonies. A higher proportion of smooth colonies was also observed by using the gradient plate technique (Freimer, Krause \& McCarthy, 1959) with $100 \mu \mathrm{g}$. bacitracin $/ \mathrm{ml}$. in the centre well.

Similar results with regard to growth inhibition were obtained with Mycobacterium tuberculosis BCG, although considerably higher concentrations of bacitracin were required to cause a strong inhibition (Fig. 2).

\section{Influence of culture media on the effects of bacitracin}

Bacitracin showed an inhibitory action against the mycobacterial species examined when tested in Penassay or Middlebrook media (Difco). However, this effect was considerably weakened when Mycobacterium smegmatis ATCC 607 and Mycobacterium tuberculosis BCG grown in Sauton medium were tested for their susceptibility to bacitracin. Further examination pointed towards a possible inhibitor being present in this medium which presumably interfered with the action of bacitracin.

In agreement with reports on the requirements for divalent cations for the micro- 
biological activity of bacitracin (Adler \& Snoke, 1962), it was found that high concentrations of citrate $(2 \mathrm{~g} . / 1$.) were responsible for the annullment of the action of bacitracin in Sauton medium. Attempts to prepare this medium with much lower concentrations of citrate were unsuccessful because of abundant precipitation. It was also observed that when citrate $\left(2 \mathrm{~g}\right.$. $/ 1$.) or EDTA $\left(\mathrm{IO}^{-5} \mathrm{M}\right)$ were added to the other media tested, in which bacitracin was highly effective, a comparable result of decreasing the drug effect was obtained.

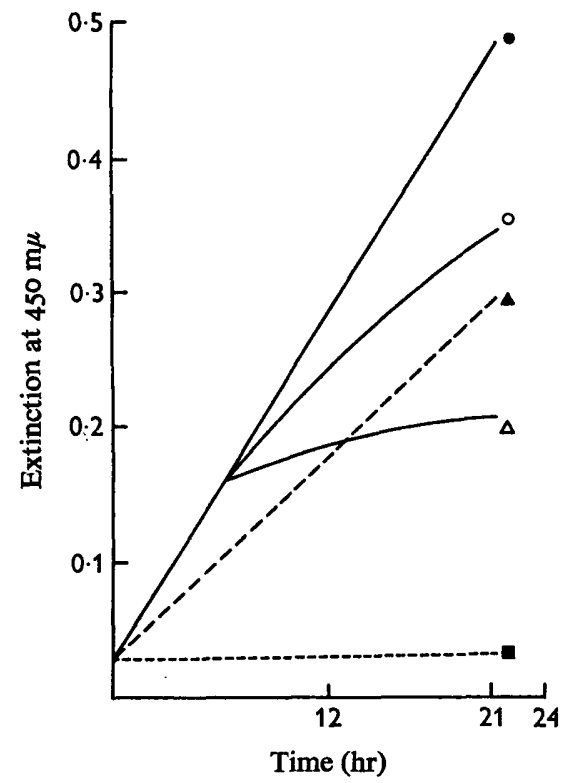

Fig I

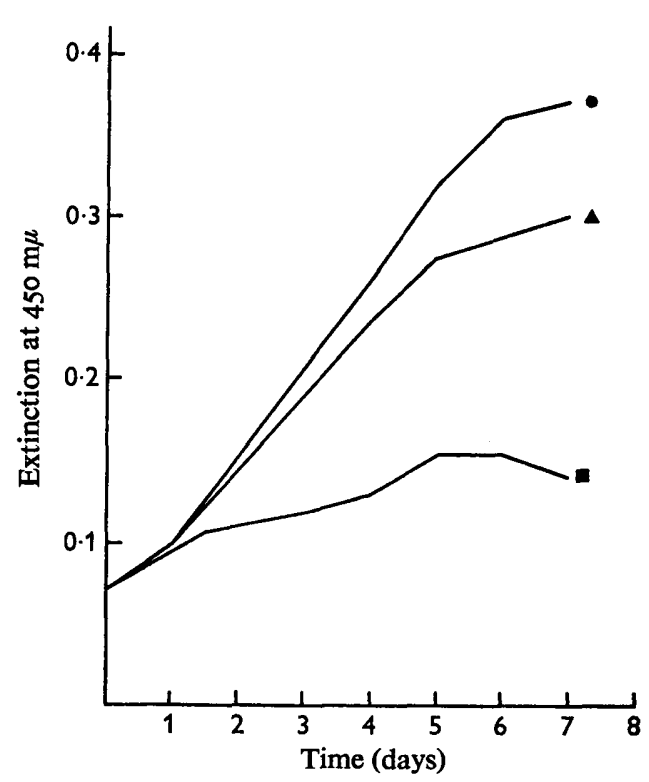

Fig 2

Fig. I. Effect of bacitracin on the growth of Mycobacterium smegmatis ATCC 607 . - Control; $\Delta 6.5 \mu \mathrm{g} . / \mathrm{ml}$.; $\mathbf{t}$ and $O_{13} .0 \mu \mathrm{g} . / \mathrm{ml}$; $\triangle 130 \mu \mathrm{g} . / \mathrm{ml}$. The drug was added at $6 \mathrm{hr}$.

Fig. 2. Effect of bacitracin on the growth of Mycobacterium tuberculosis BCG. - Control; $\Delta 13.0 \mu \mathrm{g} . / \mathrm{ml}$; $130 \mu \mathrm{g} . / \mathrm{ml}$.

It has been reported (Snoke \& Cornell, 1965) that the antibiotic effect of bacitracin is promoted by cadmium ions at $10^{-4}$ to $10^{-5} \mathrm{M}$. Although concentrations of cadmium ions at $10^{-5} \mathrm{M}$ or higher were apparently effective in enhancing the effect of bacitracin when tested in Sauton medium, it was found that such concentrations of cadmium were by themselves inhibitory to the mycobacteria tested.

\section{Ultrastructure studies}

In exponentially growing mycobacteria treated with bacitracin, multilamellaf structures occurred nearby the plasma membrane (Pl. I, fig. I, 2). The thickness or each lamella, measuring approximately $25 \AA$, was identical to that of the plasma membrane. Frequently, these lamellar structures surround low-density spaces which contain granular substances (Pl. I, fig. 2). The fact that the outer two layers of the lamellae continued to the plasma membrane (P1. I, fig. 2) indicated the lamellar struc- 
tures were derived from the plasma membrane. Noteworthy was the finding that multitubular structures of mesosomes observed in the control bacteria at the same growth (Pl. I, fig. 3) were not seen after bacitracin treatment.

Some of the bacteria contained no ribosomes nor well-defined nuclear filaments, leading us to suggest that they had undergone degeneration (P1. I, fig. 4). In these bacteria, lamellar structures usually composed of three layers containing a denser and slightly thicker central layer were distributed throughout the cytoplasm. Specimens at various sectioning angles did not evidence any cross-sectioned features of tubules, and furthermore, no tubular substance was encountered in negatively stained materials after disruption of the bacteria. These findings implied that the lamellar structures in ultrathin sections were three-dimensionally constituted of membranous layers.

Negative staining with moderate positive stain effect showed cell walls of surviving bacteria after bacitracin treatment at low concentration which differed significantly from those of control bacteria in exponential growth. Fibrillar components in mycobacterial cell walls of untreated bacteria (P1. 2, fig. 5) (Imaeda, Kanetsuna \& Galindo, I968) were partially evident on the bacitracin-treated bacterial surface which was mainly covered with irregularly shaped substances (P1. 2, fig. 6). This cell wall alteration cannot be visualized in ultrathin sections, because of non-osmiophilic characteristics of these fibrils (Imaeda, 1965).

Because of the effect of bacitracin on plasma membranes and mesosomes, a possible action of bacitracin on isolated mesosomes was examined. Mesosomes were prepared from exponentially growing Mycobacterium smegmatis ATCC 607 by differential centrifugation in sucrose $0.25 \mathrm{M}$ plus phosphate buffer ( $\mathrm{pH}_{7 \cdot 0}$; Cesari, Imaeda \& Rieber, unpublished data). Ultrastructural examination of the fractions exposed to bacitracin up to I $\mathrm{mg} . / \mathrm{ml}$. showed no appreciable difference from the untreated controls.

\section{DISCUSSION}

The observations described here show that mycobacterial growth is inhibited by bacitracin. The fact that higher concentrations of bacitracin were required to inhibit the growth of Mycobacterium tuberculosis BCG may be due to permeability factors resulting from the higher lipid content in the wall of BCG as compared with that of the rapidly growing species (Imaeda, Kanetsuna \& Galindo, I968). The significant decrease of the effect of bacitracin in Sauton medium emphasizes the importance of selecting an adequate culture medium, without a high concentration of chelators, when assaying a cation-requiring antibiotic.

Although bacitracin is highly bactericidal to mycobacteria during the middle or $l_{\text {ate }}$ exponential growth phase, its addition did not produce an immediate effect. This action was only manifested after a lapse of time after the addition of bacitracin, as shown in Fig. I. Furthermore, the initial sign of ultrastructural changes was represented by derangement of plasma membranes and mesosomes. Low concentrations of bacitracin modified cell-wall components resulting in the formation of smooth surface colonies on solid media, showing minimal structural damage of membranes without influencing cellular viability (Pl. I, fig. I, 2). However, higher concentrations of bacitracin produced severe changes in the membrane causing the disappearance of mesosomes (PI. I, fig. 4) and finally death of the organism. From this evidence, it is presumed that bacitracin interferes with membrane components. which not only 


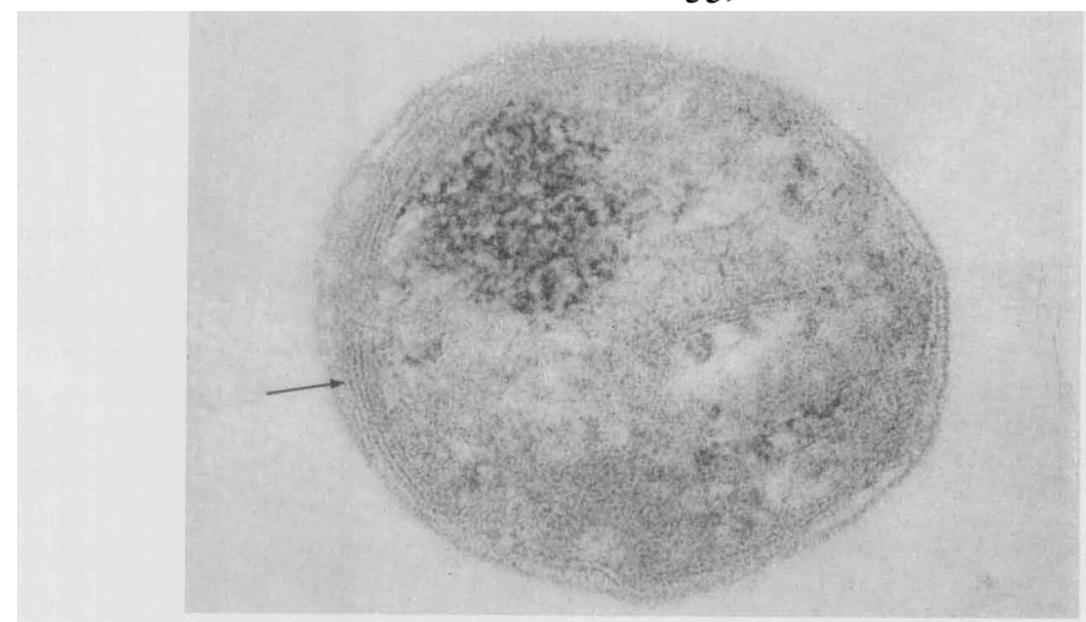

Fig. I

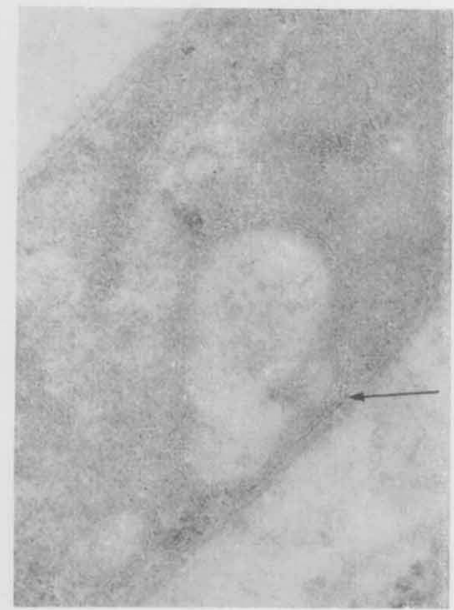

Fig. 2

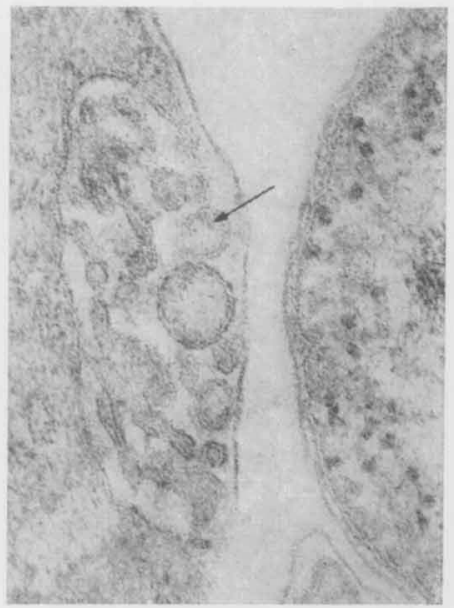

Fig. 3

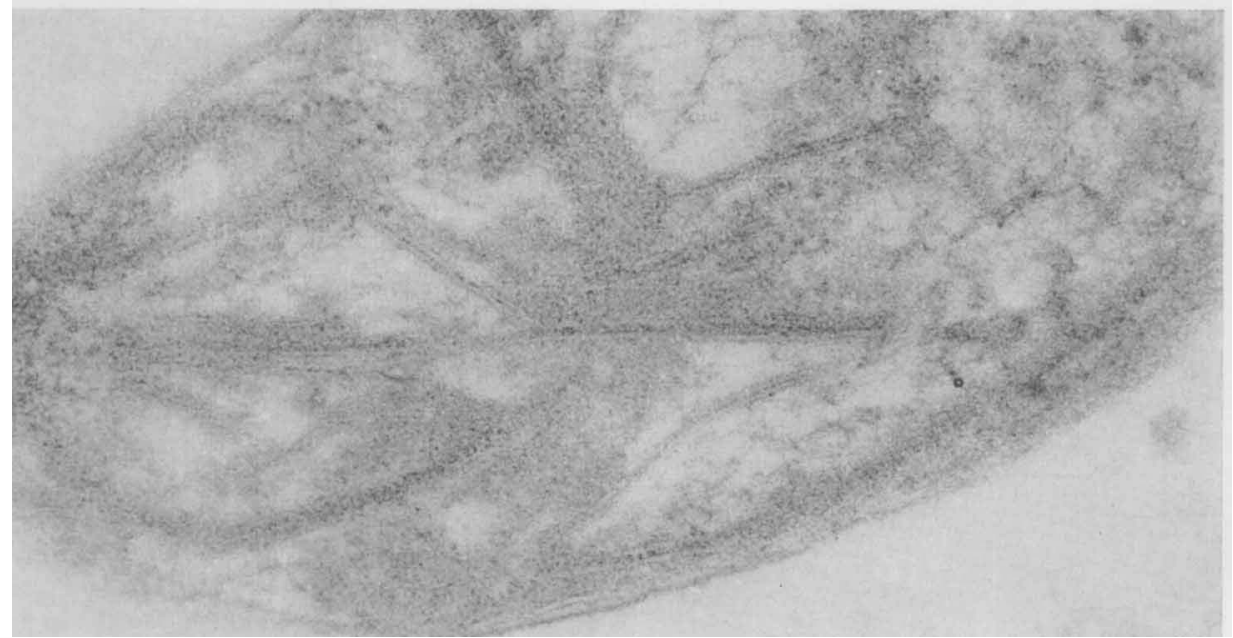

Fig. 4 
Journal of General Microbiology, Vol. 55, No. I

Plate 2

Fig. 5

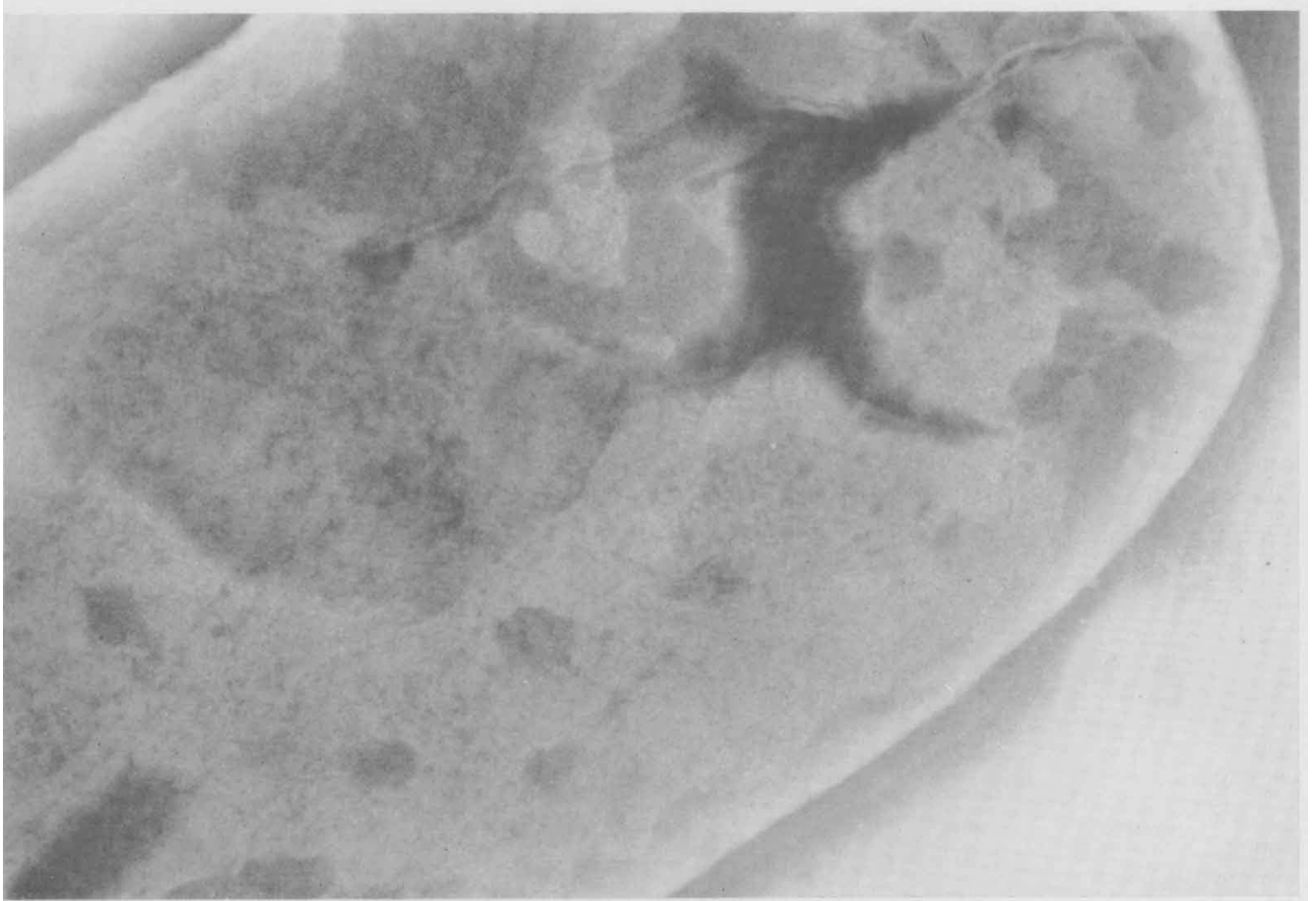

Fig. 6

M. RIEBER, T. IMAEDA AND I. M. CESARI 
maintain cellular integrity but may also contain enzymatic systems to synthesize cellwall constituents (Hancock \& Fitz-James, 1964; Imaeda \& Ogura, 1963). It is proposed that bacitracin interferes with cellular division and leads to bacterial death because of membrane disorganization.

This investigation was supported by Public Health Service Research Grants AI-04815 and 07888 from the U.S. National Institutes of Allergy and Infectious Diseases.

\section{REFERENCES}

Abraham, E. P. \& Newton, G. G. F. (1958). Structure and function of some sulphur-containing peptides. In CIBA Symposium on Amino Acids and Peptides with Anti-Metabolic Activity. Ed. by G. E. W. Wolstenholme \& C. M. O'Connor. London: Churchill.

AdLER, R. H. \& SNOKE, J. E. (1962). Requirement of divalent metal ions for bacitracin activity. J. Bact. 83, 1315.

Freimer, E. H., Krause, R. M. \& McCarthy, M. (1959). Studies of L forms and protoplasts of group A streptococci. J. exp. Med. I10, 853.

Hancock, R. \& Fitz-James, P. C. (1964). Some differences in the action of penicillin, bacitracin and vancomycin on Bacillus megaterium. J. Bact. 87, 1044.

IMAEDA, T. (1965). Electron microscopy approach to leprosy research. Int. J. Leprosy 33, 669.

IMAEDA, T. \& OGURA, M. (1963). Formation of intracytoplasmic membrane system of mycobacteria related to cell division. J. Bact. $85,150$.

IMAEDA, T., KANETSUNA, F. \& GALINDO, B. (1968). Ultrastructure of cell wall of genus Mycobacterium. J. Ultrastruc. Res. (In the Press).

SMrTH, J. L. \& WEINBERG, E. D. (1962). Mechanisms of antibacterial action of bacitracin. J. gen. Microbiol. 28, 559.

SNOKE, J. E. \& CORNELL, N. (1965). Protoplast lysis and inhibition of growth of Bacillus licheniformis by bacitracin. J. Bact. 89, 4I5.

StOECKENIUS, W. \& ROWEN, R. (1967). A morphological study of Halobacterium halobium and its lysis in media of low salt concentration. J. cell. Biol. 34, 365 .

SUTTER, L. S. \& VAUGHAN, B. F. (1955). The effect of antibacterial agents on the growth of Actinomyces bovis. Antibiotics and Chemotherapy 5, 557.

\section{EXPLANATION OF PLATES}

Plate 1

Fig. I. Bacitracin $(6.5 \mu \mathrm{g} . / \mathrm{ml}$.) treated Mycobacterium smegmatis. Note a multilamellar structure (arrow). Magnification: $\times 200,000$.

Fig. 2. Bacitracin $(6.5 \mu \mathrm{g} . / \mathrm{ml}$.) treated Mycobacterium smegmatis. Multilamellae continue to the plasma membrane (arrow). Granular substances are surrounded by these lamellae. Magnification: $\times 150,000$.

Fig. 3. Control cell at exponential growth phase. Tubular infoldings form a mesosome (arrow). Magnification: $\times 150,000$.

Fig. 4. Mycobacterium smegmatis treated with bacitracin ( $13.0 \mu \mathrm{g} . / \mathrm{ml}$.$) . Lamellar structures are$ scattered throughout the cytoplasm. Magnification: $\times 225,000$.

\section{Plate 2}

Fig. 5. Negatively stained control of Mycobacterium smegmatis with moderate positive staining effect at exponential growth phase. Note fibrillar substances covering the cell surface. Magnification: $\times 120,000$.

Fig. 6. Negatively stained Mycobacterium smegmatis with moderately positive staining effect after the treatment of bacitracin $(6 \cdot 5 \mu \mathrm{g} . / \mathrm{ml}$.). Fibrillar substances are scarcely distributed in the cell wall. Magnification: $\times 120,000$. 